\title{
AEROBIC EXERCISE AND AMELIORATED ENDOTHELIAL FUNCTION IN EXPERIMENTAL PREECLAMPSIA IN RAT MODEL $p$
}

\author{
By \\ Manal S. Abd-El Hamid \\ Department of Medical Physiology, Faculty of Medicine, Ain Shams University
}

\begin{abstract}
Background: Preeclampsia is a life threatening state. Aerobic exercise has a beneficial effect on vascular endothelium function. Adropin is a newly discovered peptide that can increase by exercise and decreased in endothelial dysfunction.
\end{abstract}

Objectives: Detecting the effect of practicing exercise on preeclampsia pathophysiology, and role of adropin.

Patients and Methods: Twenty four adult female albino wistar rats were divided into 3 equal groups: group I: Sham-operated Time-mated pregnant rats (Sham), group II: Reduced uterine perfusion pressure pregnant rats (RUPP); placental ischemia was induced at gestation day (GD) 14 to mimic preeclampsia, and group III: exercise treated reduced uterine perfusion pressure pregnant rats (Ex-RUPP); swimming started from GD1 till the end of pregnancy period, 1h/day, 6 days/week added to preeclampsia induction. Maternal arterial blood pressure, micro-albuminuria, serum urea, creatinine and calculated glomerular filtration rate (GFR), plasma insulin, glucose and calculated HOMA-IR and placental eNOS, adropin, soluble fms-like tyrosine kinase 1 (sFlt-1), malondialdehyde (MDA), total antioxidant capacity (TAC), and TNF- $\alpha$ were measured. Placental and fetal tissues were weighed and placenta was histo-pathologically assessed.

Results: Aerobic exercise during pregnancy caused significant reductions in all blood pressure values at GD17 and 19, serum urea, creatinine, micro-albuminuria, placental anti-angiogenic sflt-1, MDA, TNF- $\alpha$, plasma glucose, insulin and HOMA-IR. In addition, exercise significantly increased the calculated creatinine clearance, placental eNOS and placental adropin, placental weight, fetal weight and number. Apoptotic trophoblasts and neutrophil aggregates were absent. Adropin was significantly positive correlated with eNOS together with a significant negative correlation to mean arterial blood pressure at GD19, sflt-1, MDA, insulin and HOMA-IR .

Conclusion: Aerobic exercise, through increasing adropin level, was able to restore the angiogenic balance, and to decrease the oxidative stress, and inflammatory and insulin resistance states, thus improving endothelial function. This was reflected in improvement in the renal functions, blood pressure reduction with better maternal and fetal outcome.

Key words: Reduced uterine perfusion pressure- pre-eclampsia-Aerobic exercise- Adropin- angiogenesiseNOS.

\section{INTRODUCTION}

Preeclampsia is a life-threatening disorder that complicates $5-8 \%$ of all pregnancies especially in developing countries (Armaly et al., 2018).
Preeclampsia is defined clinically as pregnancy-induced hypertension with proteinuria, reduced renal function and multi-organ dysfunction (Hanson and Stallone, 2016). Also, preeclampsia is the major cause of prenatal death, preterm 


\section{MANAL S. ABD-EL HAMID}

deliveries and intrauterine growth restriction (IUGR) (Li et al., 2012).

The initiating cause of preeclampsia is unknown but the studies declared that abrupt remodeling of the uterine spiral arteries plays a key role in the pathogenesis of early onset preeclampsia (Cakmak et al., 2017). The ischemic placenta releases cytokines, reactive oxygen species, pro-hypertensive and anti-angiogenic factors (Cindrova-Davies, 2009).

The oxidative stress and the imbalance between the anti-angiogenic factors and pro-angiogenic factors are thought to cause endothelial dysfunction (Cakmak et al., 2017).

(O'Brien et al., 2017) stated that preeclampsia is a systemic vascular disease characterized by generalized endothelial damage. (Armaly et al., 2018) added that soluble sFlt-1 and soluble endoglin (sEng) hinder vascular endothelial growth factor release. Also, the nitric oxide (NO)/nitric oxide synthase (NOS) system might be deranged in preeclampsia (Phipps et al., 2016).

Exercise stimulates the expression of a number of cytoprotective molecules and can hold therapeutic potential (Gilbert et al., 2012). (Genest et al., 2012) stated that exercise training has shown benefits on normal pregnancy, but its impact on reducing the risk of preeclampsia has long been argued.

Exercise might restore the angiogenic imbalance associated with preeclampsia (Weissgerber et al., 2010), or lower diastolic blood pressure in pregnancyinduced hypertension (Gilbert et al., 2012). On the other side, studies claimed

that acute exercise during pregnancy reduces placental blood flow, increases inflammation and exacerbates preeclampsia (? sterdal et al., 2009). Also, (Rudra et al., 2008) claimed that physical activity in the year before pregnancy was not associated with reduced preeclampsia risk. However, (Fortner et al., 2011) denied the impact of physical activity before pregnancy on preeclampsia risk.

Adropin is a peptide hormone discovered by (Kumar et al., 2008), and it plays a significant role in energy metabolism (Zhang et al., 2017).

Adropin is encoded by the Energy Homeostasis Associated gene (gene symbol: Enho) which is expressed in many tissues including vascular endothelium (Cakmak et al., 2017).

Adropin may promote vascular health and increase endothelial cell proliferation (Lovren et al., 2010). Low plasma adropin was closely associated with endothelial dysfunction (Yu et al., 2014).

(Cakmak et al., 2017) added that low circulating adropin levels have been associated with insulin resistance, endothelial dysfunction and severe preeclampsia. (Muter et al., 2018) observed that adequate decidual adropin production may be essential for successful spiral artery remodeling in pregnancy .

(Fujie et al., 2015) related the reduction in arterial stiffness after aerobic exercise training to the concomitant elevated serum adropin levels. Also, exercise was able to increase the serum level of adropin in obese adolescents (Zhang et al., 2017).

This study was planned to examine the ability of practicing exercise during 
pregnancy to attenuate preeclampsia pathophysiology, and to examine the role of adropin in mediating these effects.

\section{PATIENTS AND METHODS}

Experimental animals: Animals used in this study were 24 adult female albino wistar rats weighing 200-250 g. Rats were purchased from the Research Institute of Ophthalmology (Giza) in which animal mating was done. Pregnant rats were accommodated in the Medical Ain Shams Research Institute (MASRI), Faculty of Medicine, Ain-Shams University. Animals were housed in animal cages $(50 \times 30 \times 20) \mathrm{cm}, \quad(4$ rats / cage $)$ with suitable ventilation, temperature of 22$25^{\circ} \mathrm{C}$, and normal dark/light cycle. Food and water access were ad libitum.

All rats were treated in accordance with the Guide for Care and Use of Laboratory Animals, and the study protocol was approved by the Research Ethical Committee of Faculty of Medicine, Ain Shams University.

Experimental groups: Rats were allocated into 3 equal groups:

\section{Group I: Sham-operated time-mated pregnant rats (Sham).}

Group II: Reduced uterine perfusion pressure pregnant rats (RUPP). Placental ischemia was induced at day 14 gestation to mimic preeclampsia ( $\mathrm{Li}$ et al., 2012).

Group III: Exercise Treated Reduced uterine perfusion pressure pregnant rats (Ex-RUPP). The swimming exercise regimen started from day 1 gestation till the end of pregnancy period, 1h/day, 6 days/week (Rocha et al., 2014). These rats were also subjected to placental ischemia at day 14 gestation.

Animal mating was performed in the Research Institute of Ophthalmology, animal house (Giza). Female rat estrous cycle phase was determined by vaginal smears based on the presence of nonnucleated cornified epithelial cells. Rats in the estrous cycle were allowed to mate overnight with employing a ratio of $1: 1$ male/female. Vaginal smears were observed for the presence of spermatozoa by the light microscopic. The day at which the smear was sperm positive was designed as gestation day 0 (GD0) (Shivananjappa, 2012).

Pre-eclampsia was induced by reduction in uterine perfusion pressure (RUPP) procedure (Li et al., 2012).

Swimming Exercise protocol: Rats were allowed to swim for 10 days before mating, $15 \mathrm{~min} /$ day to become familiar with water. Starting from gestational day 1, the rats in the EX-RUPP group started swimming for $30 \mathrm{~min}$ that were progressively lengthened to $60 \mathrm{~min}$. Rats swam 6 days per week until the end of pregnancy (Rocha et al., 2014).

The swimming bath was filled with thermally controlled water $(24 \square \mathrm{C} \pm 1)$. It length was $100 \mathrm{~cm}$, width $70 \mathrm{~cm}$, and depth $70 \mathrm{~cm}$. The presence of strong fan of 1425 revolutions/min ensure strong water currents to uniform temperature and force rat active swimming. The water bath was cleaned and water was changed after each swimming session.

Arterial blood pressure was measured before RUPP at GD13, then at GD 17, 19 before sacrifice. The blood pressure was measured in un-anesthetized rats, using rat 
tail cuff sphygmomanometer blood pressure system (NIBP200A).

Rats were housed in metabolic cages for 24 hours, to determine 24 hours urine volume used in Creatinine clearance rate (Ccr) calculation and to assess microalbuminuria.

On the day of the experiment, gestational day 20 (GD20), overnight fasted rats from Sham, RUPP and ExRUPP groups were weighed and anesthetized with intra-peritoneal injection of sodium thiopental (EPICO, Egypt) in a dose of $40 \mathrm{mg} / \mathrm{kg}$ body weight. Abdominal blood samples were collected into two tubes: EDTA tube $(0.2 \mathrm{mg})$ to measure plasma insulin and glucose levels, and plastic tube to measure serum urea and creatinine. Blood samples were centrifuged at $4000 \mathrm{rpm}$ for 10 minutes. Both uterine horns were identified behind coils of intestine and exposed. The rat pups number was counted and their crown-rump length was measured in $\mathrm{cm}$. The placental tissues were harvested for biochemical measurements and were fixed in formalin for histopathological assessment. Rat pups and placentae were isolated, washed with normal saline and dried by filter paper to be weighed in 5-Digit-Metler balance (AE 163).

Serum and urine creatinine based on Jaffé reaction (Tietz, 1995), and serum urea based on modified Urease Berthelot reaction (Young, 1995) were detected. The kits were purchased from Diamond Diagnostics Company, GmbH (Germany). Microalbuminuria based on solid phase immunoassay (EIA), read at $450 \mathrm{~nm}$, Padtan ELM kit (Rowe et al., 1990).
Creatinine clearance rate was calculated according to the equation (Bazzano et al., 2015):

Creatinine clearance rate $(\mathrm{Ccr})\{\mathrm{ml} / \mathrm{min}\}$ $=($ Urinary creatinine $(\mathrm{mg} / \mathrm{dl}) \mathrm{x}$ urine volume $(\mathrm{ml})) /($ Serum creatinine $(\mathrm{mg} / \mathrm{dl})$ x $1440(\min ))$

Plasma glucose was measured using oxidase- peroxidase method (Trinder, 1969), kits were supplied by Biodiagnostic, Egypt, and plasma insulin using enzyme-linked immunosorbent assay ELISA kit (Dako, Carpinteria, CA) according to (Delams, 1986) method.

HOMA-IR test was performed to estimate insulin resistance (Mathews et al., 1985): Fasting insulin (in ?U) $\mathrm{x}$ fasting glucose (in mmol/l)/ 22.5. A lower index indicated greater insulin sensitivity.

The placenta homogenates were prepared by homogenization of placenta in $10 \mathrm{~mL}$ cold phosphate buffer saline solution, followed by centrifugation at $10,000 \mathrm{rpm}$ for $15 \mathrm{~min}$ at 4 ?C. ELISA kit was used to measure placental eNOS (Cat No.MBS262105), adropin (Cat No.MBS2533588), soluble fms-like tyrosine kinase-1 (Cat No.MBS2602003) and tumor Necrosis Factor Alpha (R\&D systems Co., USA). Also, Placental malondialdehyde (MDA) level was measured by thiobarbituric acid reaction (Ohkawa et al., 1979) and placental total antioxidant capacity by the enzymatic colorimetric method (Koracevic et al., 2001).

Statistical analysis: Data were statistically described in terms of mean \pm SEM. Statistical significance of data was determined using a one-way analysis of variance (ANOVA) with post-hoc test 
(LSD). A probability value ( $\mathrm{p}$-value) less

significant.

than 0.05 was considered statistically

\section{RESULTS}

Results encountered in the present study are displayed in tables (I-IV), figures (2-5). Results are expressed as Mean \pm SEM.

Before reduction in uterine perfusion pressure (RUPP) procedure, at gestation day 13 (GD13), no significant changes were noticed in arterial blood pressure value between the different groups in all blood pressure values. At GD17 and GD19, RUPP group showed a significant increase in systolic, diastolic and mean arterial blood pressures compared to the sham group. In the Ex-RUPP systolic, diastolic and mean arterial blood pressures decreased when compared to RUPP $(\mathrm{P}<0.001)$ but were non-significant in comparison to the sham group (Fig 1).

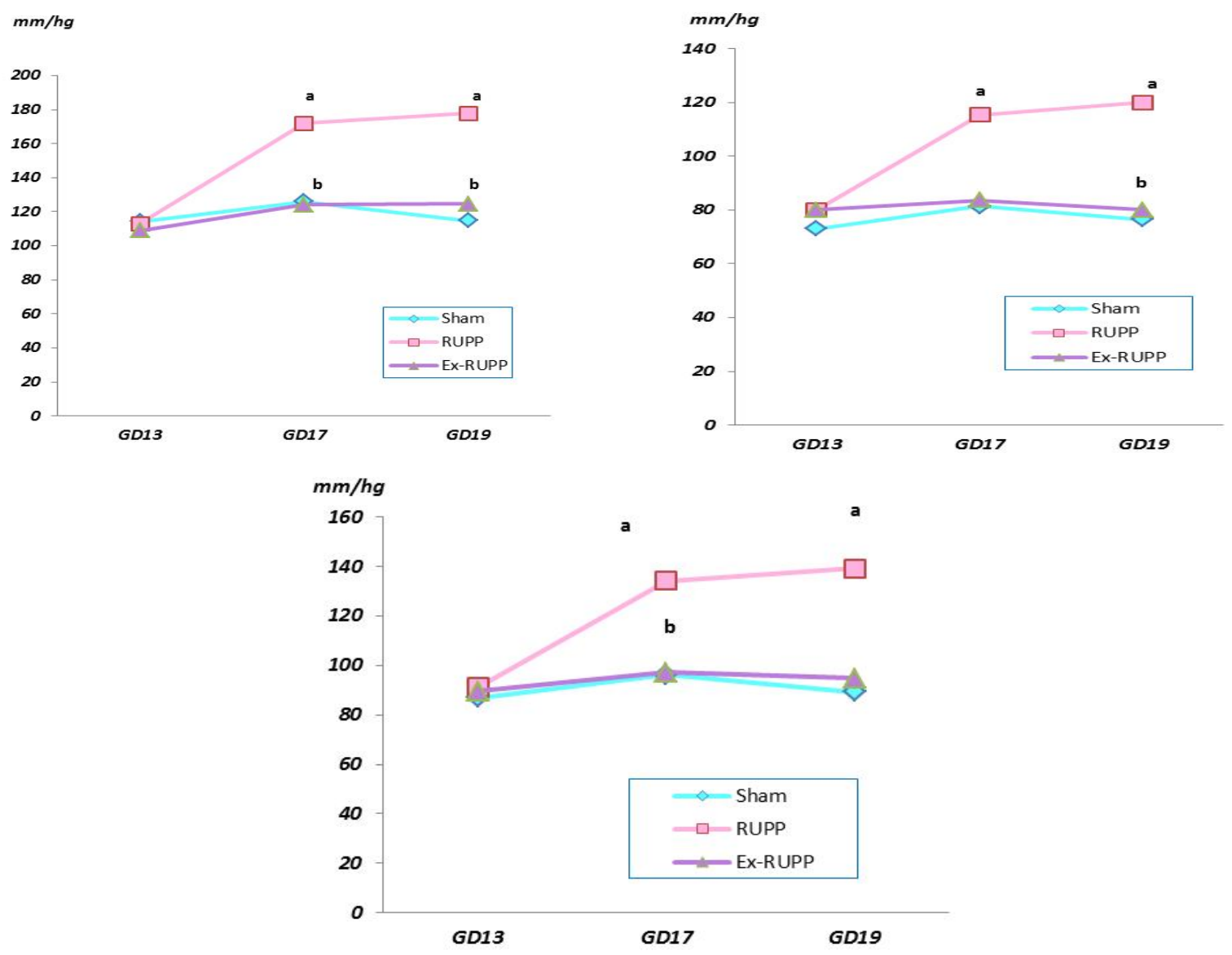

Figure (1): Systolic, diastolic and mean arterial blood pressure in all studied groups, a: Significance from sham group calculated by LSD at $P<0.05$.

b: Significance from RUPP group calculated by LSD at $P<0.05$ 
Serum urea, creatinine and microalbuminuria significantly increased $(\mathrm{P}<0.001)$ in RUPP compared to the sham group, while they significantly decreased $(\mathrm{P}<0.001)$ in Ex-RUPP compared to RUPP. Serum creatinine level became non-significant from the Sham, but serum urea and microalbuminuria remained

significantly higher $(\mathrm{P}<0.01)$ from the sham group. Calculated $\mathrm{Ccr}$ was significantly decreased in RUPP compared to sham and was significantly increased in Ex-RUPP compared to RUPP $(\mathrm{P}<0.001$ for both). Meanwhile, Ccr was significantly higher $(\mathrm{P}<0.01)$ than sham (Table I).

Table (I): Serum urea $(\mathrm{mg} / \mathrm{dl})$, serum creatinine $(\mathrm{mg} / \mathrm{dl})$, calculated Creatinine clearance rate $(\mathrm{Ccr})(\mathrm{ml} / \mathrm{min})$ and microalbuminuria $(\mu \mathrm{g} / \mathrm{ml})$ in the different groups (Mean \pm SEM)

\begin{tabular}{|l|c|c|c|}
\hline \multicolumn{1}{|c|}{ groups } & Sham & RUPP & Ex-RUPP \\
\hline parameters & $32.8 \pm 2.21$ & $91.05 \pm 3.15 \mathbf{a}$ & $57.7 \pm 8.6 \mathbf{a b}$ \\
\hline Serum urea (mg/dl) & $0.51 \pm 0.01$ & $1.24 \pm 0.10 \mathbf{a}$ & $0.67 \pm 0.12 \mathbf{b}$ \\
\hline calculated Ccr $(\mathbf{m l} / \mathbf{m i n})$ & $1.5 \pm 0.08$ & $0.19 \pm 0.02 \mathbf{a}$ & $0.94 \pm 0.13 \mathbf{~ a b}$ \\
\hline $\begin{array}{l}\text { microalbuminuria } \\
(\boldsymbol{\mu g} / \mathbf{m l})\end{array}$ & $13.45 \pm 1.2$ & $36.38 \pm 2.01 \mathbf{a}$ & $21.75 \pm 2.4 \mathbf{~ a b}$ \\
\hline
\end{tabular}

a: Significance from sham group calculated by LSD at $\mathrm{P}<0.05$.

b: Significance from RUPP group calculated by LSD at $\mathrm{P}<0.05$.

Placental eNOS and adropin significantly decreased $(\mathrm{P}<0.001)$ in RUPP compared to the sham group, while they significantly increased in Ex-RUPP compared to RUPP. Placental eNOS remained still significantly lower than the sham group $(\mathrm{P}<0.01)$. The placental anti-

angiogenic factor (sflt-1) significantly increased in RUPP compared to the sham group, while it significantly increased in Ex-RUPP compared to RUPP $(\mathrm{P}<0.001)$, being non-significant from the sham (Table II).

Table (II): Placental eNOS (ng/ml), placental adropin (ng/ml) and placental sflt-1 $(\mathrm{ng} / \mathrm{ml})$ in the different groups $($ Mean \pm SEM)

\begin{tabular}{|l|c|c|c|}
\hline \multicolumn{1}{|c|}{ Groups } & Sham & RUPP & Ex-RUPP \\
\hline $\begin{array}{l}\text { parameters } \\
\text { (ng/ml) }\end{array}$ & $96.68 \pm 4.5$ & $41.21 \pm 3.93 \mathrm{a}$ & $72.22 \pm 8.28 \mathrm{ab}$ \\
\hline Adropin (ng/ml) & $3.5 \pm 0.3$ & $1.22 \pm 0.11 \mathrm{a}$ & $3.14 \pm 0.38 \mathrm{~b}$ \\
\hline placental sflt-1 (ng/ml) & $1.14 \pm 0.12$ & $2.79 \pm 0.13 \mathrm{a}$ & $1.42 \pm 0.18 \mathrm{~b}$ \\
\hline
\end{tabular}

a: Significance from sham group calculated by LSD at $\mathrm{P}<0.05$.

b: Significance from RUPP group calculated by LSD at $\mathrm{P}<0.05$.

Placental MDA and TNF- $\alpha$ significantly increased $(\mathrm{P}<0.001)$ in RUPP compared to the sham group, while they significantly decreased $(\mathrm{P}<0.001)$ in $\mathrm{Ex}-$

RUPP compared to RUPP, but TNF- $\alpha$ remained still higher $(\mathrm{P}<0.001)$ than sham. Placental TAC did not change between the groups (Table III). 
Table (III): Placental MDA (nmol/), TAC (mM/l) and TNF- $\alpha(\mathrm{pg} / \mathrm{ml})$ in the different groups (Mean \pm SEM)

\begin{tabular}{|c|c|c|c|}
\hline parameters $\quad$ Groups & Sham & RUPP & Ex-RUPP \\
\hline MDA (nmol/) & $15.26 \pm 1.65$ & $27.08 \pm 1.75 \mathrm{a}$ & $14.47 \pm 1.07 \mathrm{~b}$ \\
\hline TAC (mM/l) & $3.83 \pm 0.5$ & $4.52 \pm 0.52$ & $3.29 \pm 0.59$ \\
\hline TNF- $\alpha(\mathrm{pg} / \mathrm{ml})$ & $1.59 \pm-.16$ & $6.51 \pm 0.54 \mathrm{a}$ & $3.84 \pm 0.45 \mathrm{ab}$ \\
\hline
\end{tabular}

a: Significance from sham group calculated by LSD at $\mathrm{P}<0.05$.

b: Significance from RUPP group calculated by LSD at $\mathrm{P}<0.05$.

Plasma glucose, insulin and HOMA-IR significantly increased $(\mathrm{P}<0.001)$ in RUPP compared to the sham group, while they significantly decreased $(\mathrm{P}<0.05, \quad<0.01$ and $<0.001$ respectively) in Ex-RUPP compared to RUPP. Plasma glucose and HOMA-IR were still higher than sham $(\mathrm{P}<0.05)$, while plasma insulin was nonsignificant from the control (Table IV).

Table (IV): Plasma glucose (m mol/l), plasma insulin ( $\mu \mathrm{IU} / \mathrm{L})$, HOMA IR in the different studied groups (Mean \pm SEM)

\begin{tabular}{|l|c|c|c|}
\hline Groups & Sham & RUPP & Ex-RUPP \\
\hline parameters & $6.91 \pm 0.47$ & $15.25 \pm 1.23$ a & $11.17 \pm 1.27$ ab \\
\hline plasma glucose $(\mathbf{m ~ m o l} / \mathbf{l})$ & $9.72 \pm 0.41$ & $18.28 \pm 1.66 \mathbf{~ a}$ & $12.11 \pm 0.49 \mathbf{b}$ \\
\hline HOMA IR & $2.99 \pm 0.24$ & $12.32 \pm 1.35 \mathbf{~ a}$ & $6.02 \pm 0.7$ ab \\
\hline
\end{tabular}

a: Significance from sham group calculated by LSD at $\mathrm{P}<0.05$.

b: Significance from RUPP group calculated by LSD at $\mathrm{P}<0.05$.

Placental and fetal weights, fetal number and length significantly decreased $(\mathrm{P}<0.001)$ in RUPP compared to sham. In Ex-RUPP placental weight, fetal weight and fetal number significantly increased compared to the sham $(\mathrm{P}<0.01,0.05$ and
0.001 respectively). Placental weight and fetal number remained higher than sham $(\mathrm{P}<0.01$ and $<0.001$ respectively $)$. Fetal length did not significantly change from RUPP or sham group (Fig. 2). 

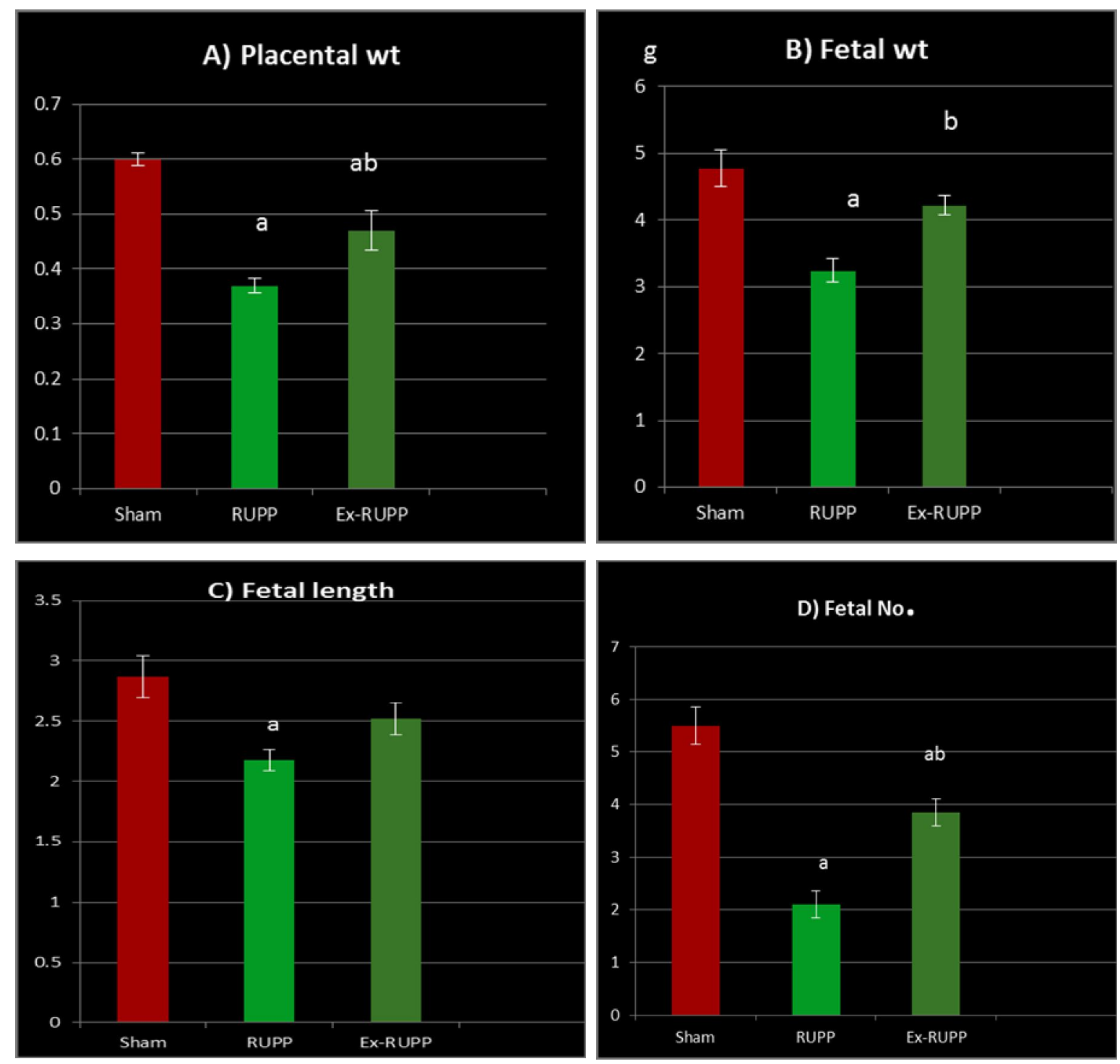

Figure (2): Maternal and fetal parameters in all studied groups

a: Significance from sham group calculated by LSD at $\mathrm{P}<0.05$.

b: Significance from RUPP group calculated by LSD at $\mathrm{P}<0.05$.

Placental adropin showed a significant positive correlation with Mean arterial blood pressure at GD19 and placental eNOS, and also showed a significant negative correlation with the antiangiogenic placental sflt-1 placental MDA, plasma insulin and HOMA-IR (Fig.3). 


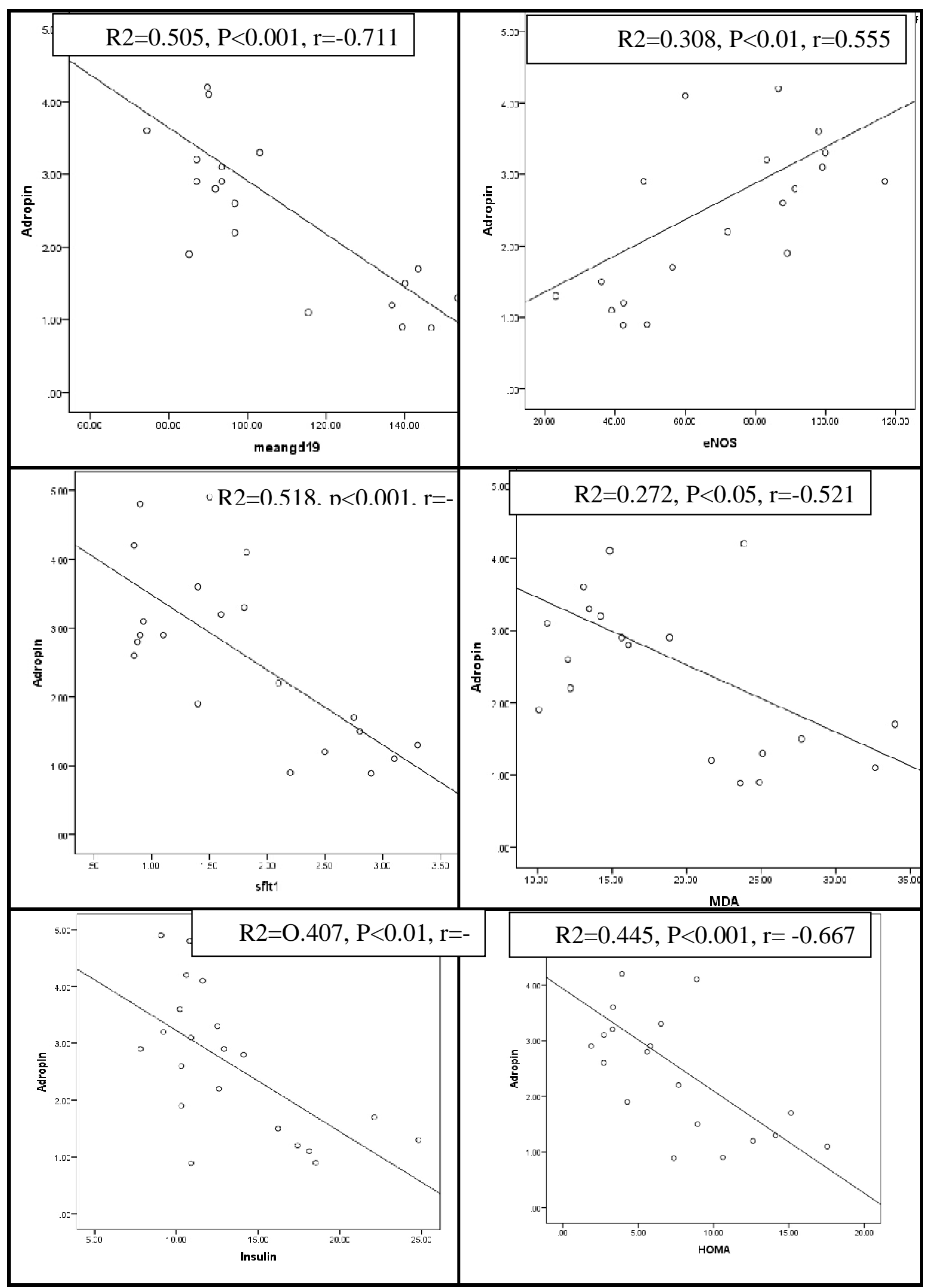

Figure (3): Regression lines and coefficients of determination (R2) between placental adropin and a) MAP GD19, b) eNOS, c) sflt-1 and d) MDA e) insulin f) HOMA-IR in all groups 
In the sham group, rat placenta showed average giant cell layer with invasion of blood vessels by trophoblastic cells, average trophospongium with average trophoblastic cells, average blood vessels and excess glycogen cells with intact cell membranes, average labyrinth zone with average maternal sinusoids, average fetal blood capillaries containing nucleated red cells, and average trophoblastic septa composed of cytotrophoblas and synsytiotrophoblasts. In RUPP group, rat placenta showed relatively thin giant cell layer with dilated congested blood vessels. Trophospongium showed dilated
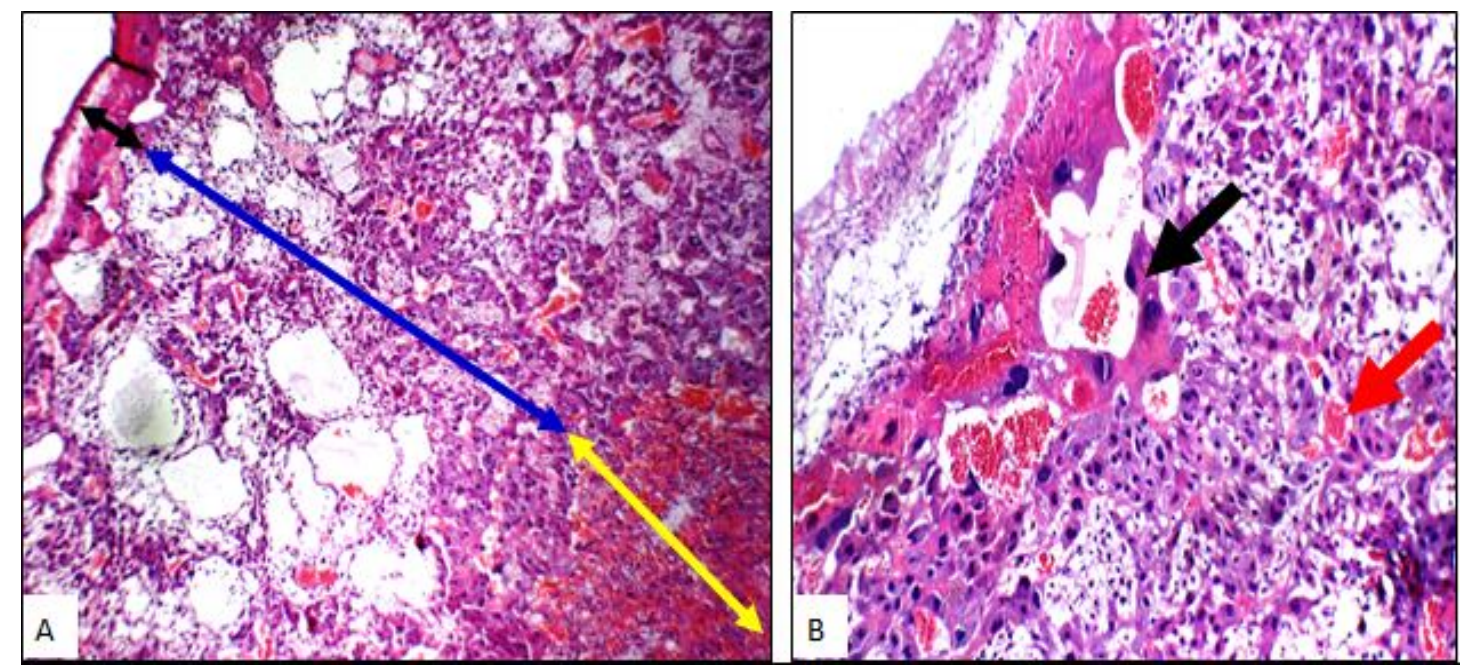

Figure (4A): Sham: Average giant cell layer (black arrow), average trophospongium (blue arrow), and average labyrinth zone (yellow arrow) (H\&E X 100)

Figure (4b): Sham: High power view showing average giant cell layer with invasion of blood vessels by trophoblastic cells (black arrow), and average trophospongium showing average blood vessels (red arrow) and excess glycogen cells (blue arrows) (H\&E X 200) congested blood vessels, marked cystic spaces, marked cytolysis of glycogen cells, apoptotic trophoblastic cells with areas of necrosis, hemorrhage and neutrophilic infiltrate, and expanded labyrinth zone with markedly dilated congested maternal blood sinusoids with intra-vascular fibrin, few fetal blood vessels containing nucleated red cells with degenerated trophoblastic septa. Rat placenta in Ex-RUPP regained giant cell layer width, and restored intact cell membranes with absence of neutrophilic infiltrate (Fig. 4). 

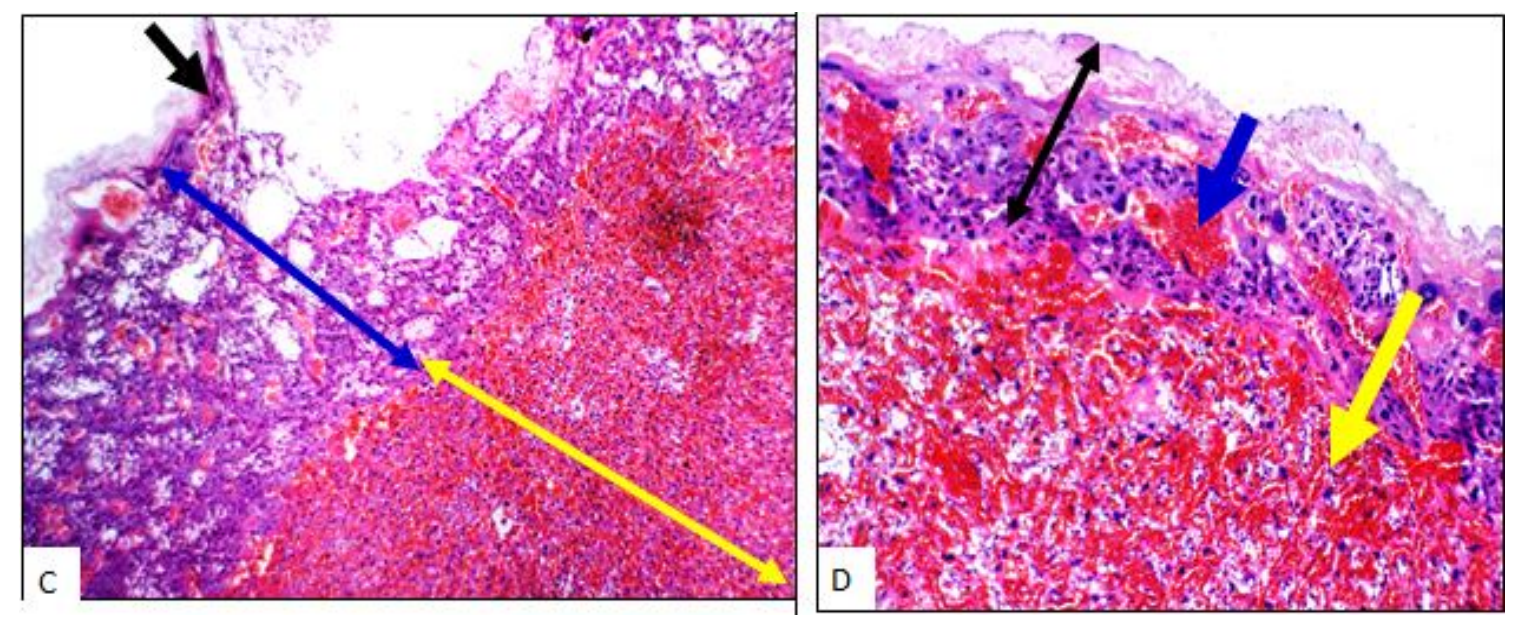

Figure (4c) RUPP: Relatively thin giant cell layer (black arrow), trophospongium (blue arrow) showing marked cystic spaces (red arrow) with areas of necrosis (green arrows), and expanded labyrinth zone (yellow arrow) (H\&E X 100)

Figure (4D) RUPP: Relatively thin trophospongium (black arrow) with markedly dilated congested blood vessels (blue arrows), and markedly congested labyrinth zone (yellow arrow) (H\&E X 200)

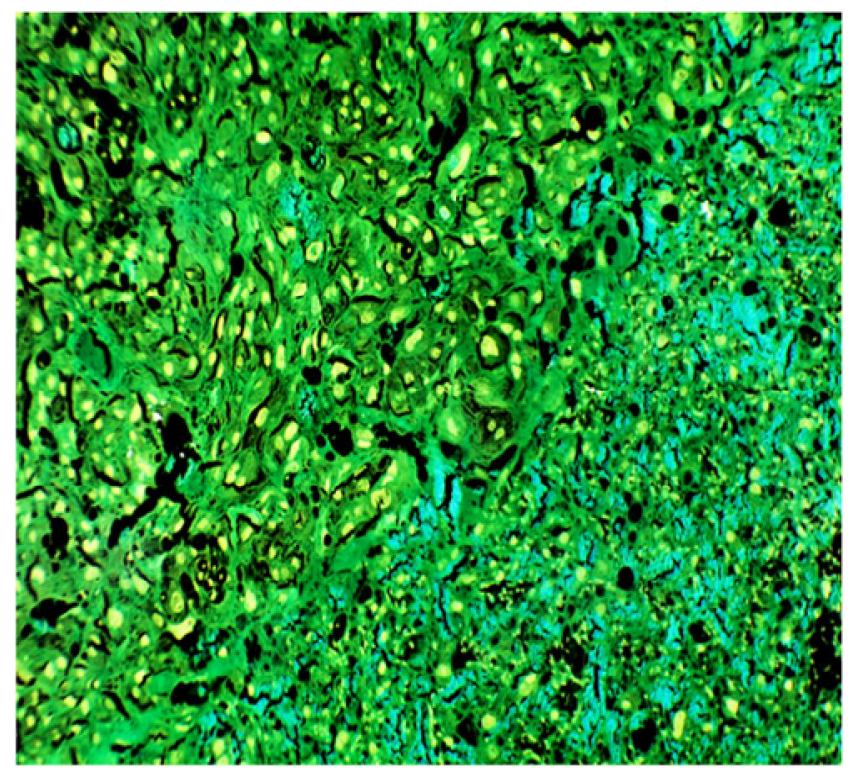

Figure (4E): Ex-RUPP: Average trophospongium, average blood vessels (red arrow) and average trophoblastic cells (blue arrows), and average labyrinth zone (black arrow) (H\&E X 200) 


\section{DISCUSSION}

The present study unraveled the ability of aerobic exercise during pregnancy to decrease pre-eclampsia associated pathological manifestations as pregnancyinduced hypertension, proteinuria and fetal growth restriction. Moreover, it elucidated the role of adropin hormone in mediating the beneficial effects of exercise.

The pre-eclampsia induction was based on uterine blood flow reduction through uterine artery ligation ( $\mathrm{Li}$ et al., 2012). RUPP rat mimicked pre-eclampsia evidenced by the significant elevation in all blood pressure values at GD17 and 19 in this group compared to the sham group, inspite of the normal blood pressure values recorded before the operation. In addition, serum urea, creatinine and microalbuminuria significantly increased, and calculated creatinine clearance significantly decreased in RUPP compared to the sham group. Preeclampsia-induced renal dysfunction with pathognomonic glomerular endotheliosis and proteinuria considered to be integral parts of pre-eclampsia disorder (Powe et al., 2011).

The encountered hypertension is multifactorial, it could be attributed to the release of many pro-hypertensive and anti-angiogenic factors from the placenta following ischemia (Cindrova-Davies, 2009). This agrees with the significant elevation in the anti-angiogenic factor soluble fms-like tyrosine kinase-1 (sflt-1) together with a significant reduction in eNOS detected in this study. The elevated sFlt-1 acts as a potent scavenger of vascular endothelial growth factor (VEGF) and placental growth factor
(PlGF) which indirectly prevents the production of VEGF-induced NO, resulting in exaggerated vasoconstriction (Burke et al., 2016). (Ahmed, 2011) added that ischemic placenta releases soluble Endoglin (sEng), the proteolytic cleavage product of endoglin, which suppresses eNOS expression leading to vasoconstriction and adhesion molecules overexpression. Both sEng and sFlt-1 act synergistically to induce endothelial dysfunction (Santner-Nanan et al., 2009) resulting in generalized vasoconstriction.

In addition, secondary to this vasoconstriction, blood flow is reduced in all organs with consequent neurohormonal activation of the sympathetic nervous system and renin angiotensin aldosterone system (RAAS) as well as endothelin (ET1) (George et al., 2012), augmenting endothelial dysfunction and hypertension.

Endothelial dysfunction was assured by the significant decrease in placental eNOS and adropin in RUPP. Adropin is effective marker for the evaluation of endothelial function (Gozal et al., 2013). Endothelial adropin can induce nitric oxide synthase (eNOS) gene expression, and ensure nitric oxide bioavailability (Lovren et al., 2010). Accordingly, (Cakmak et al., 2017) correlated decreased adropin levels with endothelial dysfunction.

The endothelial dysfunction was perpetuated owing to the increased reactive species production as proved by the significant elevation in MDA levels in RUPP compared to sham. Placental ischemia is the main factor that disturbs the cellular oxidative balance, thus decreasing neuronal nitric oxide synthase 
expression and contributing to hypertension (Sedeek et al., 2008).

The downregulation of the antiinflammatory TGF- $\beta$ and heme-oxygenase 1 caused by soluble endoglin and sflt- 1 together with the elevated angiotensin and endothelin resulted in a chronic state of inflammation (LaMarca et al., 2016). (Verdonk et al., 2015) explained that sflt-1 sensitize the maternal endothelium to the pro-inflammatory TNF- $\alpha$. Similarly, in the present study, placental TNF- $\alpha$ significantly increased in RUPP denoting an inflammatory condition.

Collectively, oxidative stress, chronic inflammation, elevated anti-angiogenic factors, endothelin and angiotensin decrease renal blood flow and glomerular filtration rate, and disrupt the glomerular barrier integrity leading to proteinuria and hypertension (Armaly et al., 2018).

(Collino et al., 2008) stated that glomerular capillary endothelium and podocytes are damaged after exposure to endothelin that acts on ETA receptor. (Powe et al., 2011) reported that the swelling in glomerulus endothelial cells and the loss in endothelial fenestrations detected in pre-eclampsia are caused by the decrease in VEGF which is essential for endothelial cells survival. Their suggestion was based on a study in which podocyte selective knockout of VEGF results in proteinuria, nephrotic syndrome and endotheliosis.

Another additional factor that can enhance endothelial dysfunction, hypertension and proteinuria is the development of insulin resistance. In this study, a significant increase in plasma glucose, insulin and HOMA-IR was detected in RUPP compared to sham denoting a state of insulin resistance. Insulin resistance is the consequence of oxidative stress and inflammatory state (Chen et al., 2015). Also, it may result from the lowered adropin level with a significant negative correlation detected between them in this study. Adropin is known to improve insulin sensitivity (Muter et al., 2018). Adropin is one of the key factors predicting the presence and severity of preeclampsia (Cakmak et al., 2017). Similar to our study, fasting serum insulin was significantly higher in preeclamptic women (Moran et al., 2006).

The RUPP model mimicked preeclampsia because of the recorded significant decrease in placental and fetal weights, fetal length and number, denoting either intra uterine growth restriction or fetal resorption. This was assured by the histological findings that show apoptotic trophoblastic cells with areas of necrosis, hemorrhage and neutrophilic infiltrate. The aforementioned pathology including the increase in sFlt$1, \mathrm{TNF}-\alpha$ and MDA, and the decrease in VEGF and NO leads to endothelial dysfunction. So, fetus could not meet the required oxygen demands (Armaly et al., 2018). In addition, adropin had a role in the regulation of fetal growth and accordingly decreased levels of adropin blood could result in IUGR (Cakmak et al., 2017).

Swimming for $1 \mathrm{~h} /$ day, 6 days/week during pregnancy period was effective in reversing the increase in arterial blood pressure. All blood pressure values at GD17 and 19 decreased compared to RUPP being non-significant from the sham group. This decrease may be related to the improvement in renal function. 
Serum urea, creatinine and microalbuminria decreased significantly and calculated creatinine clearance increased significantly in EX-RUPP group compared to RUPP. This could be attributed to the ability of exercise to improve endothelial function evidenced by the significant decrease in the antiangiogenic factor sflt- 1 and the significant increase in eNOS levels.

Similarly, (Weissgerber et al., 2010) reported that exercise can increase placental growth factor and reduce sflt- 1 in pregnant woman. (Ram?rez-Vélez et al., 2013) stated that chronic exercise training increases eNOS/NO production in human placenta by increasing endothelial shear stress or by decreasing superoxide production in placental mitochondria. Also, (Falcao et al., 2010) pointed to the ability of exercise to increase placental VEGF levels in trained mice to counterbalance soluble fms-like tyrosine kinase-1 (sFlt-1) and restore the angiogenic balance.

(Zhang et al., 2017) added that aerobic exercise improves endothelial function by elevating adropin level. (Sena et al., 2013) highlighted the ability of adropin to increase eNOS level. The increase in eNOS level in turn increases the level of the nitric oxide the most important vasodilator thus reducing hypertension (Aydin et al., 2013). This agrees with the significant negative correlation between adropin and mean arterial blood pressure at GD19 together with the significant positive correlation between adropin and eNOS level detected in our study.

Moreover, exercise can normalize blood pressure, preserve renal hemodynamics and lower albuminuria by attenuating the pro-inflammatory TNF- $\alpha$, the pro-apoptotic NF-KB and reninangiotensin system components including the plasma Ang II, ACE and AT-1R levels (Agarwal et al., 2012). This agreed with the noticed significant decrease in oxidative stress marker MDA and the proinflammatory TNF- $\alpha$ in Ex-RUPP compared to RUPP group. Exercise upregulates un-coupler proteins (UCP-2), thus decreasing the generation of oxygen free radicals in the mitochondria (Bo et al., 2008) and increases the number of mitochondria rendering the body more resistant to oxidative stress, and can increase reactive oxygen species scavenging (Genest et al., 2012).

This decrease was negatively correlated to adropin level. Similarly, adropin levels negatively correlated with markers of endothelial dysfunction and oxidative injury (Yang et al., 2018). Adropin increases the catalytic subunit of NADPH oxidase that is a major source of superoxide radical generation (Tang et al., 2012).

Exercise can also reverse inflammation-related endothelial damage through reducing the pro-inflammatory markers as IL-1 $\beta$, IL-6, and tumor necrosis factor- $\alpha$, and the peripheral inflammatory markers of endothelial dysfunction such as granulocyte macrophage colony-stimulating factor, monocyte chemotactic protein-1, soluble intercellular adhesion molecule-1, and soluble vascular cell adhesion molecule-1, whereas it increases circulating antiinflammatory cytokines, such as IL-10 (Genest et al., 2012).

Consequent to the improved oxidative stress and inflammatory state following 
exercise, insulin resistance is improved (Röhling et al., 2016). This was proved by the significant decrease in plasma glucose, insulin and HOMA-IR. Plasma insulin and HOMA-IR were negatively correlated with adropin .

Adropin can improve glucose tolerance and enhance insulin action by increasing GLUT4cell-surface expression, insulininduced Akt phosphorylation and activating the pyruvate dehydrogenase $(\mathrm{PDH})$, a rate-limiting enzyme in glucose oxidation (Gao et al., 2015).

In this study, exercise caused a significant increase in fetal and placental weights and fetal number denoting its ability to halt intrauterine growth restriction. This was supported by the restoration of trophoblastic septa and the absence of apoptotic areas. In agreement with our study, (Neto and Gama, 2015) reported the ability of aerobic training to increase placenta weight and volume and cell proliferation index by increasing the endothelial growth factors, placental growth factor and insulin like growth factor .

(Weissgerber et al., 2010) recorded that placental surface area available for gas and nutrient exchange and placental growth rate significantly increased in trained women, which could explain the reduction in fetal complications associated with preeclampsia following training. (Ram?rez-Vélez et al., 2013) added that, although exercise training during pregnancy was associated with a decreased placental weight, placental efficiency increased.

\section{CONCLUSION}

Simple intervention as exercise training can be effective in reducing blood pressure, albuminuria and fetal growth restriction and control the symptoms of pre-eclampsia. Adropin hormone mediated the beneficial effects of exercise on pre-eclampsia by restoring endothelial function.

\section{ACKNOWLEDGMENT}

The authors acknowledge Dr Sayed Abdel Raheem, Assistant Professor of Histopathology, Al-Azhar Faculty of Medicine, Cairo, for the scientific help in the histopathological assessment, and Dr Laila Rashed, Professor of Medical Biochemistry and Molecular Biology, Cairo University, Faculty of Medicine.

\section{CONFLICT OF INTEREST}

No conflict of interest

\section{REFERENCES}

1. Agarwal D, Elks CM, Reed SD, Mariappan N, Majid DS and Francis J (2012): Chronic exercise preserves renal structure and hemodynamics in spontaneously hypertensive rats. Antioxid Redox Signal.,16(2):139-152.

2. Ahmed A (2011): New insights into the etiology of preeclampsia: identification of key elusive factors for the vascular complications. Thromb. Res., 127(Suppl. 3): S72-S75.

3. Armaly $Z$, Jadaon JE, Jabbour A and Abassi ZA (2018): Pre-eclampsia: Novel Mechanisms and Potential Therapeutic Approaches. Front. Physiol., 9: Article 973, 1-15.

4. Aydin S, Kuloglu T, Aydin S, Eren MN, Yilmaz M, Kalayci M, Sahin I, Kocaman N, Citil C and Kendir Y (2013): Expression of adropin in rat brain, cerebellum, kidneys, heart, liver, and pancreas in streptozotocin-induced diabetes. Mol. Cell. Biochem., 380: 73-81.

5. Bazzano T, Restel T, Porfirio LC, Souza AS and Silva IS (2015): Renal biomarkers of male 
and female Wistar rats (Rattus norvegicus) undergoing renal ischemia and reperfusion. Acta Cir Bras., 30(4):277-288.

6. Bo H, Jiang N, Ma G, Qu J, Zhang G, Cao D, Wen L, Liu S, Ji LL and Zhang Y. (2008): Regulation of mitochondrial uncoupling respiration during exercise in rat heart: role of reactive oxygen species (ROS) and uncoupling protein 2. Free Radic Biol Med., 44: 13731381.

7. Burke SD, Zsengellér ZK, Khankin EV, Lo AS, Rajakumar A, DuPont JJ, McCurley A, Moss ME, Zhang D, Clark CD, Wang A, Seely EW, Kang PM, Stillman IE, Jaffe IZ and Karumanchi SA (2016): Soluble fms-like tyrosine kinase 1 promotes angiotensin II sensitivity in preeclampsia. J. Clin. Invest., 126: 2561-2574.

8. Cakmak BD, Dundar B, Acikgoz AS, Ozgen G, Cift T, Ahmedian $R$ and Altekin Y1 (2017): The relationship between maternal and umbilical cord adropin levels with the presence and severity of preeclampsia. J Perinat Med., 45(7):879-885.

9. Chen $\mathbf{L}$, Chen $\mathbf{R}$, Wang $\mathbf{H}$ and Liang $\mathbf{F}$ (2015): Mechanisms Linking Inflammation to Insulin Resistance. Int J Endocrinol., 2015: 508409.

10. Cindrova-Davies T. (2009): Gabor than award lecture 2008: pre-eclampsia -from placental oxidative stress to maternal endothelial dysfunction. Placenta., 30 (Suppl. A): S55-S65.

11. Collino F, Bussolati B, Gerbaudo E, Marozio L, Pelissetto S, Benedetto $C$ and Camussi G (2008): Preeclamptic sera induce nephrin shedding from podocytes through endothelin-1 release by endothelial glomerular cells. Am. J. Physiol.Renal Physiol., 294: F1185-F1194.

12. Delams H G (1986): Biochemical analysis of human and animal serum for monoclonal antibodies using ELISA. Biochem., 14: 214 231.

13. Falcao S, Bisotto S, Michel C, Lacasse AA, Vaillancourt C, Gutkowska J, Lavoie JL (2010): Exercise training can attenuate preeclampsia-like features in an animal model. J Hypertens., 28:2446-2453.

14. Fortner RT, Pekow PS, Whitcomb BW, Sievert LL, Markenson G and Chasan-Taber L (2011): Physical activity and hypertensive disorders of pregnancy among Hispanic women. Med Sci Sports Exerc., 43:639-646.

15. Fujie $S$, Hasegawa $N$, Sato $K$, Fujita $S$, Sanada K, Hamaoka $T$ and Iemitsu $M$ (2015): Aerobic exercise training-induced changes in serum adropin level are associated with reduced arterial stiffness in middle-aged and older adults. Am J Physiol Heart Circ Physiol., 309(10):H1642-H1647.

16. Gao S, McMillan RP, Zhu Q, Lopaschuk GD, Hulver MW and Butler AA (2015): Therapeutic effects of adropin on glucose tolerance and substrate utilization in dietinduced obese mice with insulin resistance. Mol Metab., 4: 310-324.

17. Genest DS, Falcao S, Gutkowska J and Lavoie JL (2012): Impact of Exercise Training on Preeclampsia Potential Preventive Mechanisms. Hypertension., 60:1104-1109.

18. George E M, Palei A $C$ and Granger $J \mathbf{P}$ (2012): Endothelin as a final common pathway in the pathophysiology of preeclampsia: therapeutic implications. Curr. Opin. Nephrol. Hypertension., 21: 157-162.

19. Gilbert JS1, Banek CT, Bauer AJ, Gingery $A$ and Needham K (2012): Exercise training attenuates placental ischemia-induced hypertension and angiogenic imbalance in the rat. Hypertension., 60(6):1545-1551.

20. Gozal D, Kheirandish-Gozal L, Bhattacharjee R, Molero-Ramirez H, Tan HL and Bandla HP (2013): Circulating adropin concentrations in pediatric obstructive sleep apnea: potential relevance to endothelial function.J Pediatr.,163: 1122-1126.

21. Hanson AE and Stallone JN (2016): Preeclampsia in the rat: validation of the deoxycorticosterone (DOCA)-salt model. Fasebj., 30: No. 1 supplement. Abstract Number: 1212.10.

22. Koracevic D, Koracevic G, Djordjevic V, Andrejevic S and Cosic V (2001): Method for the measurement of antioxidant activity in 
human fluids. Journal of Clinical Pathology., 54(5):356-361.

23. Kumar KG, Trevaskis JL, Lam DD, Sutton GM, Koza RA, Chouljenko VN, Kousoulas KG, Rogers PM, Kesterson RA, Thearle M, Ferrante AW Jr, Mynatt RL, Burris TP, Dong JZ, Halem HA, Culler MD, Heisler LK, Stephens JM and Butler AA (2008): Identification of adropin as a secreted factor linking dietary macronutrient intake with energy homeostasis and lipid metabolism. Cell Metab., 8(6): 468-481.

24. LaMarca B, Amaral LM, Harmon AC, Cornelius DC, Faulkner JL and Cunningham MW Jr (2016): Placental ischemia and resultant phenotype in animal models of preeclampsia. Curr Hypertens Rep., 18(5): 38-54.

25. Li J, LaMarca B and Reckelhoff JF (2012): A model of preeclampsia in rats: the reduced uterine perfusion pressure (RUPP) model. Am J Physiol Heart Circ Physiol., 303(1): H1-H8.

26. Lovren F, Pan Y, Quan A, Singh KK, Shukla PC, Gupta M, Al-Omran M, Teoh H and Verma $S$ (2010): Adropin is a novel regulator of endothelial function. Circulation, 122: S 185-S92.

27. Mathews D. R., Hosker J. P., Rudenski A. S., Naylor B. A., Treacher D. F. and Turner R. C. (1985): Homeostasis model assessment: insulin resistance and $\beta$-cell function from fasting plasma glucose and insulin concentrations in man. Diabetologia., 28: 412419.

28. Moran C, Sandoval T, Duque X, Gonzalez S, Moran $S$ and Bermudez JA (2006): Increased insulin levels independent of gestational overweight in women with preeclampsia. Arch Med Res., 37:749-754.

29. Muter J, Alam MT, Vrljicak P, Barros FSV, Ruane PT, Ewington LJ, Aplin JD, Westwood M and Brosens JJ (2018): The Glycosyltransferase EOGT Regulates Adropin Expression in Decidualizing Human Endometrium. Endocrinology., 1;159(2):9941004.

30. Neto WK and Gama EF (2015): Exercise effect on placental components: Systemic review and meta-analysis. Rev Bras Med Esporte., 21(6): 485-489.

31. O'Brien M, Baczyk D and Kingdom JC (2017): Endothelial Dysfunction in Severe Preeclampsia is Mediated by Soluble Factors, Rather than Extracellular Vesicles. Sci Rep.; 7(1):5887,1-12.

32. Ohkawa H, Ohishi W and Yagi K. (1979): Assay for lipid peroxides in animal tissues by thiobarbituric acid reaction. Anal Biochem., 95(2):351-358.

33. ? sterdal ML, Str?m M, Klemmensen AK, Knudsen VK, Juhl M, Halldorsson TI, Nybo Andersen AM, Magnus $P$ and Olsen SF (2009): Does leisure time physical activity in early pregnancy protect against pre-eclampsia? Prospective cohort in Danish women. BJOG., 116:98-107.

34. Phipps E, Prasanna D, Brima $W$ and Jim B (2016): Preeclampsia: Updates in Pathogenesis, Definitions, and Guidelines. Clin J Am Soc Nephrol., 6; 11(6):1102-1113.

35. Powe CE, Levine RJ and Karumanchi SA (2011): Preeclampsia, a disease of the maternal endothelium: the role of antiangiogenic factors and implications for later cardiovascular disease. Circulation. ,123(24):2856-2869.

36. Ram?rez-Vélez R, Bustamante J, Czerniczyniec A, Aguilar de Plata AC and Lores-Arnaiz S (2013): Effect of exercise training on eNOS expression, NO production and oxygen metabolism in human placenta. PLoS One., 14; 8(11):e80225.

37. Rocha R, Peraçoli JC, Volpato GT, Damasceno DC and De Campos KE (2014): Effect of exercise on the maternal outcome in pregnancy of spontaneously hypertensive rats. Acta Cir. Bras. , 29 (9): 553-558.

38. Röhling $M$, Herder $C$, Stemper $T$ and Müssig K (2016): Influence of Acute and Chronic Exercise on Glucose Uptake. J Diabetes Res., 2016:2868652.

39. Rowe DJ, Dawnay A and Watts GF (1990): Microalbuminuria in diabetes mellitus: review and recommendations for the measurement of albumin in urine. Ann Clin Biochem., 27( Pt 4): 297-312. 
40. Rudra CB, Sorensen TK, Luthy DA and Williams MA (2008): A prospective analysis of recreational physical activity and preeclampsia risk. Med Sci Sports Exerc., 40(9):1581-1588.

41. Santner-Nanan B, Peek MJ, Khanam R, Richarts L, Zhu E, Fazekas de St Groth B and Nanan R (2009): Systemic increase in the ratio between Foxp3+ and IL-17-producing $\mathrm{CD} 4+\mathrm{T}$ cells in healthy pregnancy but not in preeclampsia. J Immunol.,1; 183(11):70237030.

42. Sedeek M, Gilbert JS, LaMarca BB, Sholook M, Chandler DL, Wang $Y$ and Granger JP (2008): Role of reactive oxygen species in hypertension produced by reduced uterine perfusion in pregnant rats. Am $\mathrm{J}$ Hypertens. , 21(10):1152-1156.

43. Sena CM, Pereira AM and Seiça R (2013): Endothelial dysfunction - a major mediator of diabetic vascular disease. Biochim. Biophys. Acta., 1832: 2216-22131.

44. Shivananjappa MM (2012): Taurine attenuates maternal and embryonic oxidative stress in a streptozotocin-diabetic rat model. Reproductive Biomedicine Online. 24(5):558566.

45. Tang XN, Cairns B, Kim JY and Yenari MA (2012): NADPH oxidase in stroke and cerebrovascular disease. Neurol Res., 34: 338345.

46. Tietz NW. (1995): Clinical guide to laboratory tests. 3rd Edition, AACC Press. Philadelphia. WB. Saunders, 268-273.

47. Trinder L. (1969): Determination of blood glucose using an oxidaseperoxidase system with a non-carcinogenic chromagen. Ann. Clin. Biochem., 1, 24-29.

48. Verdonk K, Saleh L, Lankhorst S, Smilde JE, van Ingen MM, Garrelds IM, Friesema
EC, Russcher H, van den Meiracker AH, Visser W and Danser AH(2015): Association studies suggest a key role for endothelin-1 in the pathogenesis of preeclampsia and the accompanying renin-angiotensin-aldosterone system suppression. Hypertension., 65(6):13161323.

49. Weissgerber TL, Davies GA and Roberts JM (2010): Modification of angiogenic factors by regular and acute exercise during pregnancy. J Appl Physiol., 108:1217-1223.

50. Yang C, DeMars KM and Candelario-Jalil E (2018): Age-Dependent Decrease in Adropin is Associated with Reduced Levels of Endothelial Nitric Oxide Synthase and Increased Oxidative Stress in the Rat Brain. Aging Dis., 9(2):322-330.

51. Young DS (1995): Effects of drugs on clinical laboratory tests. 4th Edition, Pbl. AACC Press, Washington, D. C., 3-190-3-208.

52. Yu HY, Zhao P, Wu MC, Liu J and Yin W (2014): Serum adropin levels are decreased in patients with acute myocardial infarction. Regul Pept., 190-191: 46-49.

53. Zhang H, Jiang L, Yang YJ, Ge RK, Zhou M, Hu H, Liu H, Cui J, Li LL, Dong YF, Cheng XS, Chen R and Li P (2017): Aerobic exercise improves endothelial function and serum adropin levels in obese adolescents independent of body weight loss. Sci Rep.; 7(1):17717, 1-8. 


\section{التمرينات الرباضية و وظبفة بطانة الأو عية الدموية في

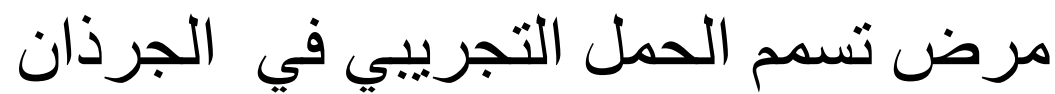 منال سعيد عبد الحميذ}

قسم الفسيولوجيا الطبية،كلية الطب،جامعة عين شمس

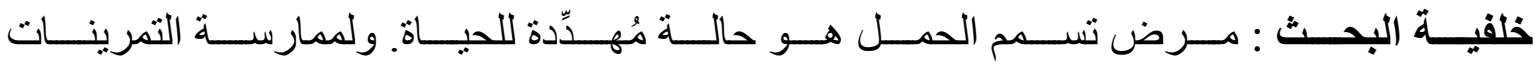

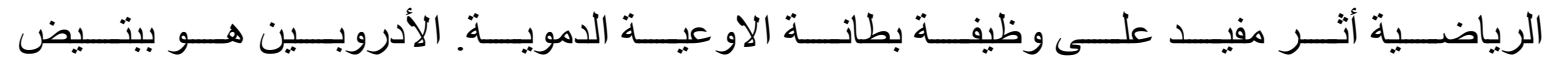

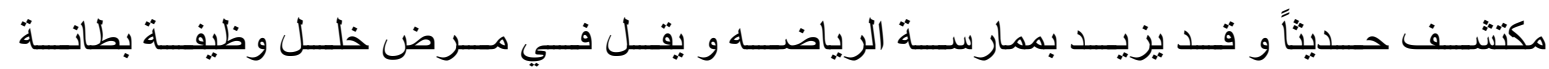
الأوعية الدموية.

الهــــف مــن البحــث: الكثــف عــن تــأثير ممارســة الرياضـــة علــى الآليــات المرضــية لتسمم الحمل و توضيح دور الأدروبين.

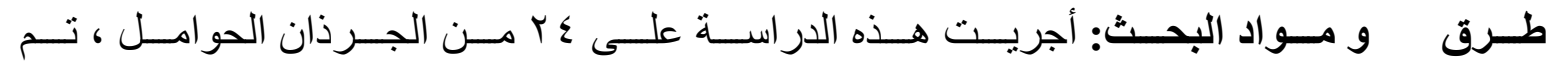
توزيعهم على ثلاث مجمو عات متساوية:

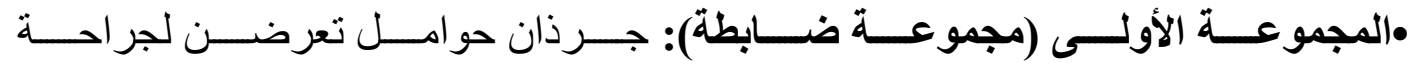
صورية.

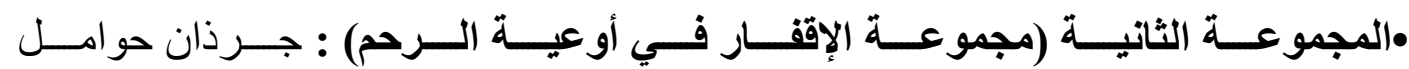

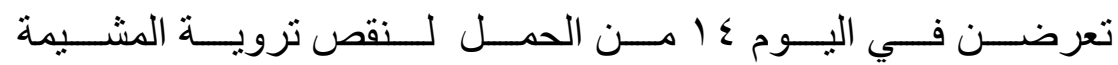
لمشابهة مرض تسمم الحمل.

•المجموعـة الثالثــة (مجموعـة معالجــة عــن طريــق ممارســة الرياضــةة): جـرذان

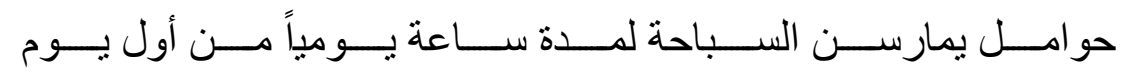

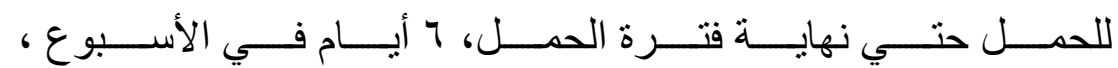
بالإضافة إلى إستحداث مرض تسمم الحمل.

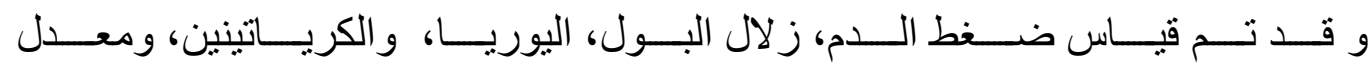

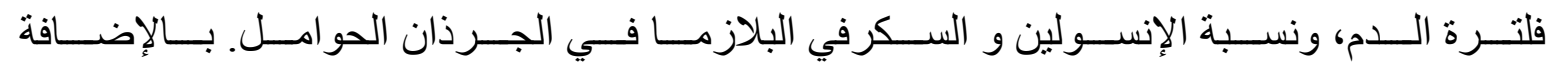
TAC ‘MDA

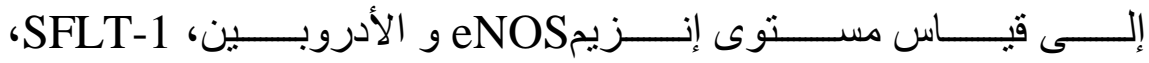


وTNFلأنسجة المشيمة.

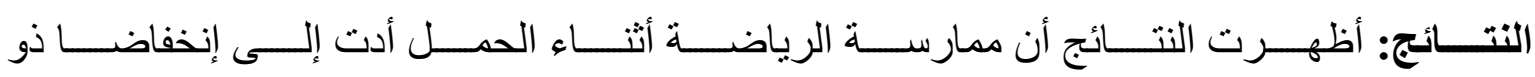

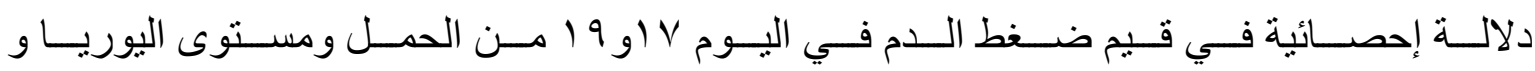

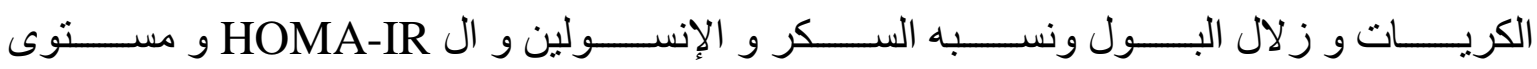

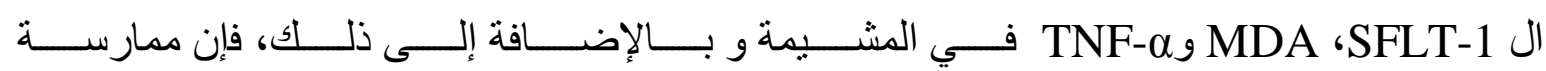

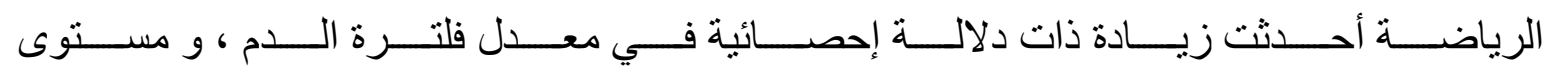

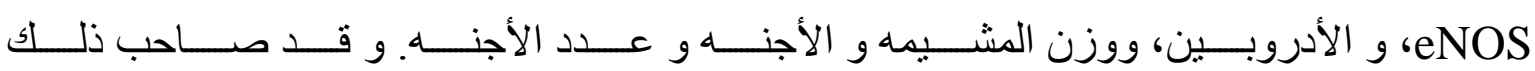

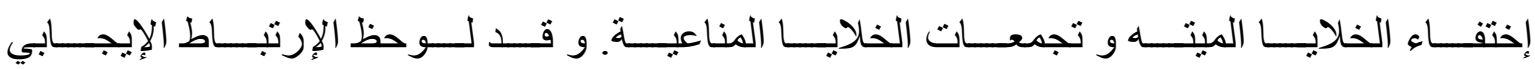

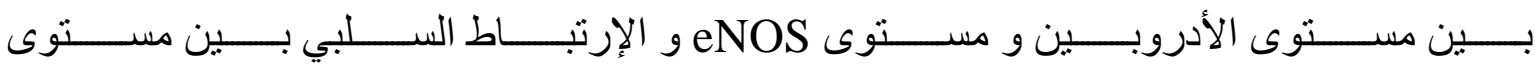

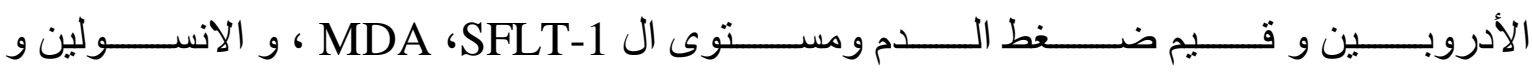
.HOMA-IR

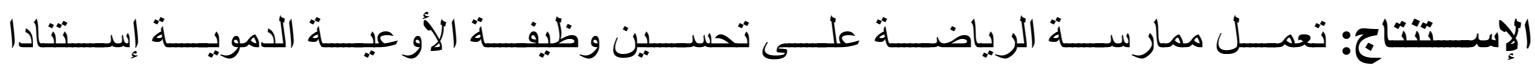

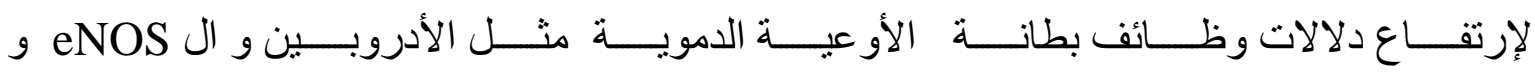

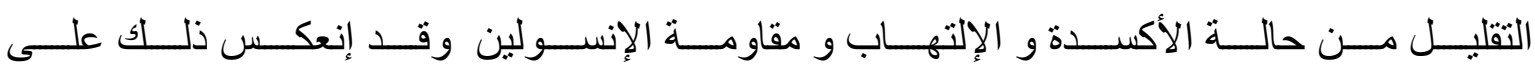

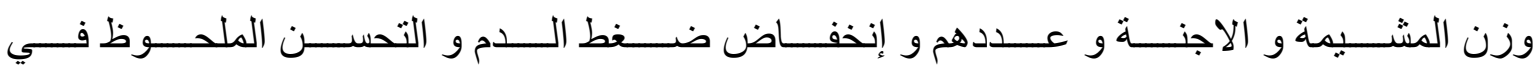

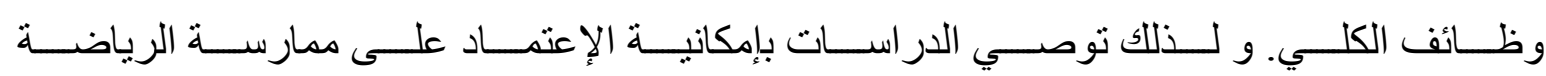
أثناء الحمل في الحد من مرض تسمم الحمل و أعر اضه. 